\title{
PENGARUH MANIPULASI AKTIVITAS RIIL TERHADAP PROFITABILITAS PERUSAHAAN LQ 45 DI BURSA EFEK INDONESIA
}

\author{
Eka Hariyani \\ Jurusan Akuntansi Fakultas Ekonomi Universitas Riau, Pekanbaru \\ Email: e.honey85@yahoo.com
}

\begin{abstract}
Abstrak:Penelitian ini menguji Pengaruh manipulasi aktivitas riil terhadap profitabilitas perusahaan LQ 45 di Bursa Efek Indonesia. Untuk menyelidiki masalah ini, studi ini menggunakan data-data dari Bursa Efek Indonesia. Sampel penelitian ini adalah perusahaan LQ 45 dari tahun 2007 hingga 2010. Berdasarkan data 2007-2010 terdapat 100 sampel perusahaan yang terdaftar secara konsisten dalam kelompok LQ 45. Hasil penelitian ini membuktikan bahwa: (1) 63 (63 \%) data sampel terbukti melakukan manipulasi aktivitas riil melalui arus kas operasi, oleh karena sampel arus kas operasi abnormal di bawah o rerata. (2) Tidak terdapat pengaruh manipulasi aktivitas riil terhadap profitabilitas perusahaan LQ 45, karena nilai signifikansi manipulasi aktivitas riil memiliki probabilitas 0,718 lebih besar dibandingkan $\mathrm{a}=0,05$, nilai t hitung $0,362(\mathrm{P}=0,718>0,05)$. (3) Perusahaan yang melakukan manipulasi aktivitas riil menunjukan profitabilitas yang rendah dibandingkan dengan profitabilitas perusahaan yang tidak melakukan manipulasi aktivitas riil. Manipulasi aktivitas riil dipergunakan untuk menstabilkan profitabilitas atau mencapai target profitabilitas tertentu atau menghindari laporan keuangan perusahaan yang merugi.

Kata kunci: Arus kas operasi, manipulasi aktivitas riil dan profitabilitas.
\end{abstract}

\section{PENDAHULUAN}

Pasar Modal adalah bursa yang merupakan sarana untuk mempertemukan penawar dan permintaan dana jangka panjang dalam bentuk efek. Pasar modal memiliki peranan penting dalam kegiatan ekonomi. Di banyak negara terutama di negara-negara yang menganut sistem ekonomi pasar, pasar modal telah menjadi salah satu sumber kemajuan ekonomi. Sebab pasar modal dapat menjadi sumber dana altenatif bagi perusahaan-perusahaan. Perusahaanperusahaan ini merupakan salah satu agen pro-duksi, yang secara nasional akan membentuk gross domestic product (GDP). Dengan berkembangnya pasar modal akan mendorong kemajuan ekonomi suatu negara (Kepres No. 6o Tahun 1988).

Pelaku pasar modal memerlukan informasi dari laporan keuangan perusahaan untuk mengambil keputusan investasi dalam suatu perusahaan. Salah satu komponen laporan keuangan yang menjadi pertimbangan bagi investor dalam mengambil keputusan investasi adalah laporan arus kas operasi. Laporan arus kas operasi menjadi laporan yang penting bagi investor, karena dalam keadaan di atas normal skala total asset akan meng-indikasikan tidak terdapat manipulasi aktivitas riil, sedangkan jika laporan arus kas operasi rendah 
pada keadaan dibawah rerata normal skala total asset, maka mengindikasikan terdapat manipulasi aktivitas riil melalui arus kas operasi (Roychodhury 2006).

Investor dan calon investor selama ini cenderung hanya memper-hatikan profitabilitas yang terdapat dalam laporan keuangan tanpa memper-hatikan laporan arus kas operasi. Investor atau calon investor perlu evaluasi terhadap laporan arus kas operasi dan laporan profitabilitas atau laba perusahaan, hal ini dilakukan untuk mengetahui apakah terdapat indikasi manipulasi aktivitas riil melalui arus kas operasi pada laporan keuangan.

Roychowdhury (2006) menjelaskan bahwa manajemen laba dapat dilakukan dengan manajemen laba akrual murni dan manajemen laba riil atau manipulasi aktivitas riil. Manajemen laba akrual murni (pure accrual) dilakukan melalui discretionary accrual. Discretionary accrual disebut dengan manajemen laba akrual. Manajemen laba akrual dilakukan pada akhir periode ketika manajer mengetahui profitabilitas sebelum direkayasa sehingga dapat mengetahui berapa besar manipulasi yang diperlukan agar target profitabilitas tercapai. Sedangkan manajemen laba riil (real activities manipulation atau manipulasi aktivitas riil) dapat terjadi sepanjang periode akuntansi. Kegiatan manajemen laba riil dimulai dari praktik operasional yang normal, Manajemen laba riil terjadi karena manajer berkeinginan untuk menyesatkan beberapa stakeholder untuk percaya bahwa tujuan pelaporan keuangan tertentu telah dipenuhi dalam operasi normal.

Masalah manajemen laba telah memunculkan beberapa kasus skandal penggelembungan profitabilitas pada laporan keuangan pada beberapa perusahaan di Indonesia. Beberapa kasus yang cukup menarik perhatian masyarakat adalah: (1) PT.Kimia farma Tbk (I Putu Sugiartha 2010); (2) PT.Lipo Tbk; (3) Bank Global; (4) Bank Summa ( Irawan Romy 2011).

Manajemen laba riil atau manipulasi aktivitas riil adalah alat untuk mengelola profitabilitas melalui pilihan untuk mengubah waktu atau struktur dari suatu operasi, investasi dan/transaksi keuangan untuk mempengaruhi output system akuntansi (I Putu Sugiartha, 2010). Sedangkan Roychodhury (2006) mendefinisikan sebagai perbedaan arus kas kegiatan operasi aktual dengan arus kas. Profitabilitas perusahaan adalah laba perusahaan atau kelebihan harga jual dari harga pokok atau kelebihan pendapatan atas seluruh beban dan biaya (Ardiyos 2009).

Perusahaan LQ 45 merupakan perusahaan yang tergolong dalam perusahaan yang baik dan kondisi perusahaan yang stabil. Dengan kondisi seperti ini menarik untuk diketahui apakah laporan keuangan yang disajikan memang riil dari aktivitas perusahaan atau telah terjadi manipulasi aktivitas riil. Perusahaan LQ 45 merupakan perusahaan yang menyajikan laporan keuangan sangat baik sehingga sangat diminati oleh investor. Sehubungan dengan itu para manajer perusahaan LQ 45 berusaha menyajikan laporan keuangan dengan baik agar perusahaan tetap masuk dalam 45 perusahaan terbaik. Tetapi tidak menutup kemungkinan segala cara akan dilakukan oleh manajer untuk melakukan manipulasi aktivitas riil sepanjang periode akuntansi. 
Roychowdhury (2006) menyebutkan beberapa teknik manipulasi aktivitas riil antara lain penjualan produk dengan diskon harga, penjualan produk dengan kredit bunga rendah, waktu kredit yang lunak, produksi yang melebihi kebutuhan pasar, dan pengurangan biaya diskresioner untuk memenuhi target profitabilitas tertentu. Berdasarkan penjelasan di atas, rumusan hipotesis pertama sebagai berikut: "terdapat manipulasi aktivitas riil pada perusahaan LQ 45 yang dilakukan melalui arus kas operasi”.

Roychowdhury (2003) menemukan hasil penelitian bahwa Perusa-haan Compustat yang melakukan manipulasi aktivitas riil memperlihatkan arus kas kegiatan operasi yang rendah. Arus kas kegiatan operasi terkena dampak manipulasi aktivitas riil. Perusahaan melaporkan profitabilitas yang rendah yaitu perusahaan yang masuk kedalam sampel suspect melakukan manipulasi aktivitas riil, memiliki arus kas abnormal yang rendah. Fakta ini konsisten dengan perusahaan yang mencoba untuk meningkatkan pro-fitabilitas tahunan dengan cara memberikan diskon harga untuk mening-katkan penjualan serta dengan produksi besar-besaran (over-production).

Livnat dan Zarowin (1990 dalam penelitian Megawati 2009) menyatakan bahwa manipulasi aktivitas riil melalui arus kas operasi, memberikan dampak terhadap kinerja pasar perusahaan (return saham). Dengan adanya manipulasi aktivitas riil melalui arus kas operasi, maka terdapat perbedaan kinerja pasar antara perusahaan yang diduga melakukan manipulasi aktivitas riil dan perusahaan yang diduga tidak melakukan manipulasi aktivitas riil. Hal ini karena profitabilitas yang tinggi merupakan salah satu indikator perusahaan memiliki kinerja yang baik sehingga menyebabkan kenaikan harga saham atas perusahaan tersebut.

Perusahaan LQ 45 merupakan perusahaan yang menyajikan laporan keuangan sangat baik sehingga sangat diminati oleh investor. Sehubungan dengan itu para manajer perusahaan LQ 45 berusaha menyajikan laporan keuangan dengan baik agar perusahaan tetap masuk dalam 45 perusahaan terbaik, tetapi tidak menutup kemungkinan segala cara akan dilakukan oleh manajer untuk melakukan rekayasa profitabilitas perusahaan pada laporan keuangan tahunan, dan apakah terdapat pengaruh manipulasi aktivitas riil terhadap profitabilitas perusahaan LQ 45. Sehubungan dengan hal tersebut maka Hipotesis kedua sebagai berikut: "terdapat pengaruh manipulasi aktivitas riil terhadap profitabilitas perusahaan LQ 45 ”.

\section{METODE PENELITIAN}

Populasi penelitian ini adalah perusahaan-perusahaan LQ 45 yang terdaftar pada Bursa Efek Indonesia, sedangkan sampel penelitian adalah perusahaan-perusahaan LQ 45 yang terpilih sebagai sampel, dan konsisten selama pengamatan pada periode 2007-2010, serta datanya tersedia.

Teknik pengambilan sampel adalah Purposive sampling, artinya sampel dipilih dengan maksud atau tujuan tertentu, sampel memiliki informasi yang 
diperlukan bagi penelitian. Jika ukuran populasi sekitar 100, maka sampelnya paling sedikit $30 \%$. Jika ukuran populasi 30 maka sam-pelnya harus $100 \%$ (Hasan Mustafa 2000).

Prosedur pemilihan sampel penelitian menunjukan karakteristik perusahaan yang masuk kedalam perusahaan LQ 45 dari tahun 2007 sampai tahun 2010, dari hasil seleksi data terdapat 25 perusahaan yang secara konsisten berada pada periode pengamatan, sehingga total sampel berjumlah 100.

Pengujian hipotesis akan dilakukan regresi untuk mencari arus kas operasi normal. Model regresi untuk mencari arus kas operasi normal mereplikasi dari penelitian Roychowdhury (2006) sebagai berikut:

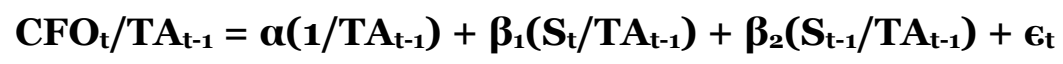

Keterangan:

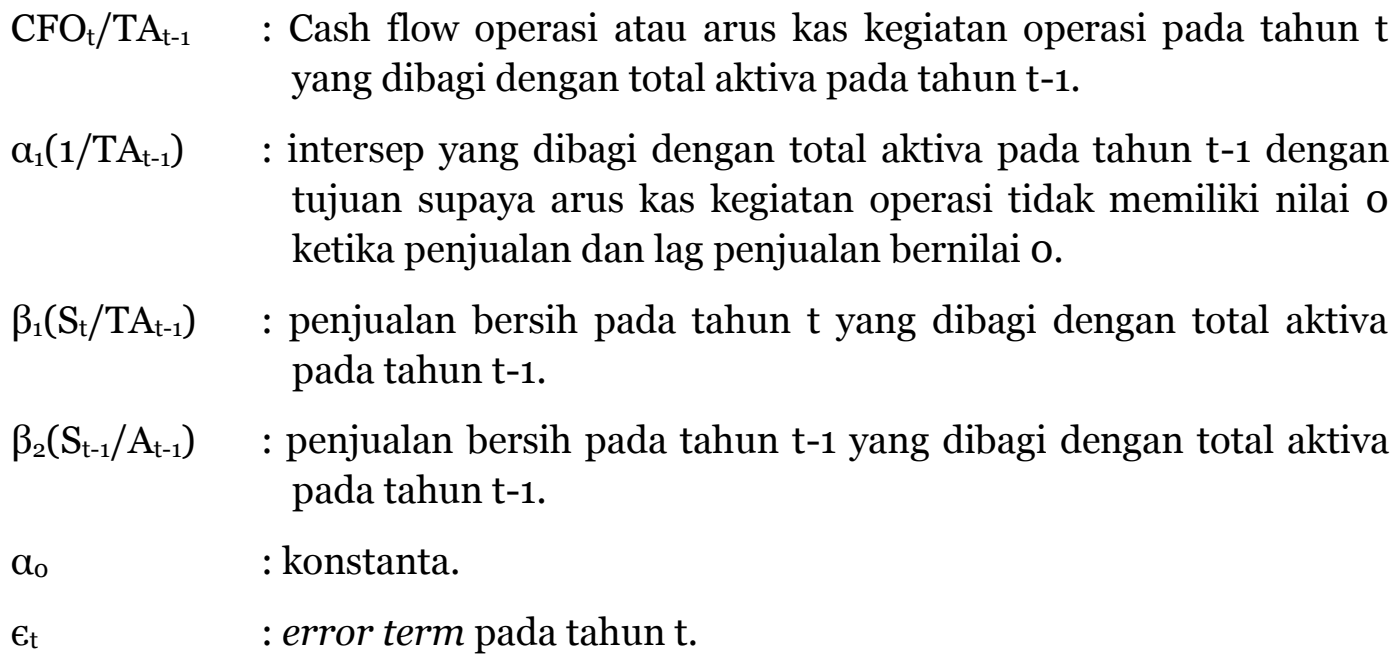

Penelitian ini akan menggunakan arus kas kegiatan operasi abnormal atau (ABN_CFO). Arus kas operasi abnormal yang merupakan selisih dari arus kas operasi aktual dikurangi dengan arus kas operasi normal. Regresi dilakukan untuk mencari nilai arus kas operasi tidak dilakukan uji asumsi klasik. Hal ini disebabkan karena nilai yang dibutuhkan adalah nilai koefisien dari hasil regresi tersebut.

Hipotesis 1 menyatakan terdapat manipulasi aktivitas riil pada perusahaan LQ 45 yang dilakukan melalui arus kas operasi. Untuk pengujian hipotesis 1 ada atau tidak manipulasi aktivitas riil melalui arus kas operasi ditentukan berdasarkan rerata dan signifikansi nilai abnormal dari arus kas operasi. Apabila arus kas operasi abnormal sampel berada dibawah rerata 0 , maka sampel melakukan manipulasi aktivitas riil melalui arus kas operasi. Sedangkan sampel yang berada di atas rerata o berarti bahwa sampel tidak melakukan manipulasi aktivitas riil melalui arus kas operasi. Nilai rerata arus kas operasi abnormal diperoleh dari statistik deskriptif seluruh sampel dengan pengujian menggunakan t-test.

Hipotesis 2 menyatakan bahwa terdapat pengaruh manipulasi aktivitas riil terhadap profitabilitas perusahaan LQ 45, untuk pengujian hipotesis 2 apakah 
terdapat Pengaruh manipulasi aktivitas riil terhadap profitabilitas perusahaan, ditentukan dengan uji $\mathrm{T}$ nilai variabel profitabilitas perusahaan group tidak manipulasi, dan group manipulasi aktivitas riil melalui arus kas operasi, apakah terdapat perbedaan, apakah perbedaan signifikan dan group mana yang lebih tinggi profitabilitasnya, dengan pengolahan data menggunakan program SPSS.

Pengujian hipotesis ini dilakukan Pertama, dengan menentukan Hipotesis Objektif (Ho) dan Hipotesis Alternatif (Ha) dari hipotesis yang akan di-uji: Kedua, melakukan Uji Beda Rata-Rata, data variabel tertentu. Ketiga, menentukan apakah hipotesis diterima atau ditolak. Jika nilai probabilitas yang didapat lebih besar dari 5 \% (0,05) maka Ho diterima dan Ha ditolak, menunjukkan bahwa perbedaan tidak signifikan. Dan jika nilai probabilitas-nya lebih kecil dari $5 \%(0,05)$ maka Ha diterima dan Ho ditolak.

\section{HASIL DAN PEMBAHASAN}

Statistik deskriptif untuk variabel-variabel yang digunakan mencari nilai arus kas operasi normal untuk keseluruhan sampel penelitian 100 sampel dari 4 tahun masa pengamatan. Adapun uji deskriptif variabel sebagai berikut:

\section{Tabel 1 Uji Deskriptif Variabel Arus Kas Kegiatan Operasi}

\begin{tabular}{cccc}
\hline Variabel & Tahun & N & Mean/rerata \\
\hline Cfo/Ta & 2007 & 25 & 0.1945 \\
& 2008 & 25 & 0.0889 \\
& 2009 & 25 & 0.1043 \\
& 2010 & 25 & 0.1106 \\
N Sales/Ta & Total & 100 & 0.1246 \\
& 2007 & 25 & 1.2439 \\
& 2008 & 25 & 1.4007 \\
& 2009 & 25 & 1.2307 \\
& 2010 & 25 & 0.4578 \\
\hline
\end{tabular}

Berdasarkan data statistik tersebut, menunjukan bahwa arus kas operasi tahun 2008, nilai rerata $8,89 \%$ dari total asset, mengalami penurunan dibandingkan tahun 2007 nilai rerata arus kas operasi yaitu: 19,45 \% dari total asset, setelah itu pada tahun 2009 rerata arus kas operasi mengalami kenaikan menjadi 10,43 \% dari total asset. Kemudian pada tahun 2010 rerata arus kas kegiatan operasi 11,06 \% dari total asset, dan rerata arus kas kegiatan operasi tahun 2007-2010 adalah 12,46 \% dari total aset.

Sedangkan Net Sales/Ta tahun 2008 yaitu: nilai rerata 140,07 \% dari total aset, mengalami peningkatan dibandingkan tahun 2007 yaitu: nilai rerata 124,39 \% dari total asset, setelah itu pada tahun 2009 rerata net sales turun menjadi $123,07 \%$ dari total asset, kemudian pada tahun 2010 rerata net sales turun menjadi 45,78 \% dari total asset, dan rerata net sales 2007-2010 adalah $108,32 \%$ dari total aset. 
Hasil analisis pengujian hipotesis pertama, yang menyatakan bahwa terdapat manipulasi aktivitas riil pada perusahaan LQ 45 yang dilakukan melalui arus kas operasi. Hasil pengujian hipótesis dapat dilihat pada tabel dibawah ini.

Tabel 2 Pengujian hipótesis 1

\begin{tabular}{llll}
\hline \multicolumn{1}{c}{ Variabel } & Rerata & Probabilitas & Keterangan \\
\hline Abn Cfo & $-0,069691$ & $0,000$. & Ha1 diterima \\
\hline Signifikan pada tingkat $=$ a $5 \%$ & & \\
\hline
\end{tabular}

Hasil pengujian hipotesis pertama menunjukan bahwa dari keseluruhan sampel yaitu 100 sampel, manipulasi aktivitas riil melalui arus kas operasi (Abn Cfo) memiliki rerata -0,069691. Karena rerata berada dibawah nilai o, maka sampel melakukan manipulasi aktivitas riil melalui arus kas operasi. Tetapi untuk membuktikan apakah nilai rerata tersebut signifikan maka dapat dilihat nilai signifikansinya. Nilai signifikansi rerata abnormal arus kas operasi memiliki nilai probabilitas sebesar 0,000 , nilai $t=10.649$. Karena nilai signifikansi lebih kecil dibandingkan $\mathrm{a}=5 \%(0,000<5 \%)$, maka hipotesis satu yang menyatakan bahwa perusahaan LQ 45 melakukan manipulasi aktivitas riil melalui arus kas operasi tidak dapat ditolak pada tingkat $=5 \%$. Dari keseluruhan sampel, maka yang melakukan manipulasi aktivitas riil melalui arus kas operasi adalah sebanyak 63 sampel (63\%).

Hasil pengujian hipotesis satu terbukti bahwa perusahaan LQ 45 melakukan manipulasi aktivitas riil melalui arus kas operasi. Adanya temuan manipulasi aktivitas riil melalui arus kas operasi konsisten dengan hasil penelitian Roychowdhury (2003) bahwa perusahaan yang melakukan manipulasi aktivitas riil melalui arus kas operasi terbukti memperlihatkan arus kas operasi yang rendah. Perusahaan terbukti melakukan manajemen laba melalui manipulasi aktivitas riil dengan cara memberikan potongan harga untuk meningkatkan penjualan, overproduction, dan pengurangan biaya diskresioner. Dengan adanya pengurangan biaya riset dan pengembangan akan berdampak pada kenaikan profitabilitas yang dilaporkan, namun menyebabkan arus kas kegiatan operasi secara abnormal rendah. Faktor-faktor yang mempengaruhi manipulasi aktivitas riil antara lain hutang, persediaan, piutang, dan pertumbuhan perusahaan (Roychowdhury 2006).

Hasil analisis pengujian hipotesis kedua, menyatakan terdapat penga-ruh manipulasi aktivitas riil terhadap profitabilitas perusahaan LQ 45.

\section{Tabel 3 Pengujian hipótesis 2}

\begin{tabular}{lrrll}
\hline \multicolumn{1}{c}{ Variabel } & Rerata & T & Probabilitas & Keterangan \\
\hline Provitabilitas & & & Ho2 diterima \\
Tidak manipulasi & 3321755.61 & 0,362 & 0,718 & \\
Manipulasi & 3066332.91 & & & \\
\hline Signifikan pada tingkat $=$ a $5 \%$ & & & \\
\hline
\end{tabular}

Hasil pengujian hipotesis kedua menunjukan bahwa dari keseluruhan sampel, maka rerata profitabilitas yang melakukan manipulasi aktivitas riil adalah 3066332.91 lebih rendah dibandingkan dengan grup tidak manipulasi 
aktivitas riil rerata profitabilitas 3321755.61. Untuk membuktikan nilai variabel profitabilitas grup manipulasi aktivitas riil tersebut apakah signifikan maka dapat dilihat nilai signifikansinya. Nilai signifikansi memiliki nilai probabilitas sebesar 0,718 , nilai t hitung 0,362 . Karena nilai signifikansi lebih besar dibandingkan $\mathrm{a}=$ $5 \%(\mathrm{p}=0,718>0,05)$, maka hipotesis kedua yang menyatakan bahwa terdapat pengaruh manipulasi aktivitas riil terhadap profitabilitas perusahaan LQ 45 tidak dapat diterima pada tingkat $=5 \%$. Hal itu berarti bahwa Ho2 diterima yaitu tidak terdapat pengaruh manipulasi aktivitas riil terhadap profitabilitas perusahaan LQ 45 .

Adanya temuan profitabilitas perusahaan menunjukan bahwa ter-dapat perbedaan rerata profitabilitas grup yang melakukan manipulasi aktivitas riil adalah 3066332.91 lebih rendah dibandingkan dengan grup tidak manipulasi aktivitas riil rerata profitabilitas 3321755.61 adalah konsisten dengan hasil penelitian Roychowdhury (2003) bahwa perusahaan yang melakukan manipulasi aktivitas riil terbukti melaporkan profitabilitas yang rendah. Arus kas kegiatan operasi terkena dampak manipulasi aktivitas riil. Perusahaan melaporkan profitabilitas yang rendah yaitu perusahaan yang masuk kedalam sampel suspect melakukan manipulasi aktivitas riil, memiliki arus kas abnormal yang rendah. Fakta ini konsisten dengan perusahaan yang mencoba untuk meningkatkan profitabilitas tahunan dengan cara memberikan diskon harga untuk meningkatkan penjualan serta dengan produksi besar-besaran (overproduction). Manajemen laba dengan cara manipulasi aktivitas riil merupakan manipulasi yang dilakukan oleh manajemen melalui arus kas operasi. Manipulasi aktivitas riil merupakan alternatif lain dari manajemen laba yang sulit dideteksi oleh auditor. Hal ini disebabkan karena aktivitas riil tersebut dilakukan melalui tindakan atau aktivitas riil sehari-hari yang dapat terlihat atau strategi yang dilakukan oleh perusahaan.

Manipulasi aktivitas riil melalui arus kas operasi dipergunakan untuk menstabilkan profitabilitas, atau untuk mencapai target profitabilitas tertentu atau untuk menghindari laporan keuangan perusahaan yang merugi.

\section{KESIMPULAN}

Hasil penelitian menunjukan sebagai berikut: 1) terdapat manipulasi aktivitas riil pada perusahaan LQ 45 yang dilakukan melalui arus kas operasi, dari 100 data sampel, maka sampel yang melakukan manipulasi aktivitas riil sebanyak 63 data sampel, karena arus kas operasi menunjukan nilai rendah dibawah o rerata; 2) Tidak terdapat pengaruh manipulasi aktivitas riil terhadap profitabilitas perusahaan LQ 45, oleh karena berdasarkan hasil uji t variabel profitabilitas yang melakukan manipulasi aktivitas riil Nilai signifikansi memiliki probabilitas sebesar 0,718 , nilai t hitung 0,362 . Karena nilai signifikansi lebih besar dibandingkan $\mathrm{a}=5 \%(\mathrm{p}=0,718>0,05) ; 3)$ Perusahaan yang melakukan manipulasi aktivitas riil menunjukan lebih rendah profitabilitasnya dibandingkan dengan profi-tabilitas perusahaan yang tidak melakukan manipulasi aktivitas riil. 
Adanya temuan profitabilitas perusahaan menunjukan bahwa ter-dapat perbedaan rerata profitabilitas grup yang melakukan manipulasi aktivitas riil adalah 3066332.91 lebih rendah dibandingkan dengan grup tidak manipulasi aktivitas riil rerata profitabilitas 3321755.61 adalah konsisten dengan hasil penelitian Roychowdhury (2003) bahwa perusahaan yang melakukan manipulasi aktivitas riil terbukti melaporkan profitabilitas yang rendah. Manipulasi aktivitas riil melalui arus kas operasi dipergunakan untuk menstabilkan profitabilitas, atau untuk mencapai target profitabilitas tertentu atau untuk menghindari laporan keuangan perusahaan yang merugi.

Rekomendasi sebagai berikut: Penelitian selanjutnya diharapkan dapat menemukan lebih banyak lagi aktivitas tentang manipulasi aktivitas riil, selain arus kas operasi antara lain arus kas kegiatan pendanaan atau pembiayaan dapat dimasukan kedalam penelitian, dalam rangka agar hasil penelitian mengenai pengaruh manipulasi aktivitas riil terhadap profi-tabilitas perusahaan LQ 45 akan lebih valid.

\section{DAFTAR PUSTAKA}

Ardiyos, 2009, Kamus Besar Akuntansi, Citra Harta Prima, Jakarta.

Hasan Mustafa, 2000, www.Unpar.ac.id. (27-8-2013,p 9,37), Universitas Parahiyangan.

I Putu Sugiarta, 2010, The Effect of Real Activities Manipulation to Accrual Earning Management, Jornal FE UI.

Indonesian Capital Market Directory (ICMD), BEI, 2007, 2008, 2009. 2010 www.idx.go.id.

Irawan Romy, 2011, Analisis dan Pengaruh Manajemen Laba Akrual dan Aktivitas Nyata terhadap Penawaran Right Issu serta Kinerja Jangka Panjang pada Perusahaan yang melakukan Penawaran Right Issu, di BEI, USU, Medan, 2011, dipublikasikan.

Livnat dan Zarowin (1990), The Incremental Information Content of Cash Flow Components, Journal of Accounting and Economic Vol.13: 25-46

Megawati, dan Yanthi Hutagaol, 2009, Analisis Arus kas Operasi dalam Mendeteksi manipulasi Aktivitas Riil dan Dampaknya terhadap Kinerja Pasar, Jurnal Riset Akuntansi Indonesia, Vol.12 No.1 Januari, 2009.

Roychowdhury,S, 2003. Management of earnings through the manipulation of real activities that affect cash flow from operations. Working paper. Sloan School of Management, 2003.Available at, www.ssrn.com, University of Rochester, USA.

Roychowdhury,S, 2006, Earning management troough real activities manipulation, Journal of Accounting and Economics, 42; 335-370, University of Rochester, USA. 